\title{
Two mechanisms that account for major histocompatibility complex restriction of $\mathrm{T}$ cells
}

\author{
David M Kranz
}

Address: Department of Biochemistry, University of Illinois, 600 South Mathews Avenue, Urbana-Champaign, IL 61801, USA

Email: d-kranz@illinois.edu

FI000 Biology Reports 2009, I:55 (doi:10.34I0/BI-55)

The electronic version of this article is the complete one and can be found at: http://FI000.com/Reports/Biology/content///55

\begin{abstract}
In recent studies, two distinct mechanisms have been proposed to account for major histocompatibility complex (MHC) restriction of T-cell activity: (a) evolution-driven interactions between T-cell receptor (TCR) variable regions and MHC, and (b) a requirement for CD4 or CD8 binding to MHC to initiate signalling through the TCR complex. Both mechanisms are likely to be essential, but for different reasons.
\end{abstract}

\section{Introduction and context}

Since the discovery that $\mathrm{T}$ cells are restricted by products of the major histocompatibility complex (MHC) [1], there has been considerable interest in understanding their molecular and structural basis. The process that yields a T-cell repertoire restricted to MHC ligands occurs in the thymus and is called positive selection [2]. Simply put, if the $\alpha \beta$ T-cell receptor (TCR) does not have some basal binding affinity for MHC, then the $\mathrm{T}$ cell dies.

Despite two decades of study, the underlying mechanism that accounts for MHC restriction by T cells has remained unclear and, to some extent, controversial. In the last several years, two mechanisms that could account for MHC restriction and positive selection have made their way to the forefront. One mechanism involves observations that germline-encoded TCR variable (V) regions appear to have evolved residues that interact with the MHC. The other mechanism relies on a signalling requirement: the TCR/CD3 complex must be brought together with the co-receptors $\mathrm{CD} 4$ or CD8 upon cobinding of the MHC product. While in principle one could make the case that one of these proposed mechanisms is more important than the other, various considerations (including the low affinity threshold for positive selection and the diversity of TCRs) lead to the conclusion that both mechanisms are important.
Major recent advances

Germline-encoded TCR regions evolved to bind $\mathrm{MHC}$ products

Based on various studies, it was reasonable to expect that the structures of a collection of TCR:pepMHC complexes would reveal a clear mechanistic basis of MHC restriction [3-6]. For example, there could have been contacts between conserved TCR residues and conserved regions of MHC and these interactions could have accounted not only for MHC restriction, but for the ability of a TCR to distinguish class I from class II MHCs. To the surprise of many, there were few discernable atomic interactions that were conserved, although there was a conserved, roughly diagonal docking pattern of TCR on MHC [7-9].

In hindsight, these structural analyses were complicated by the diversity of TCRs and the variety of pepMHC ligands that were represented among the complexes. Once several TCR:pepMHC structures that shared TCR regions were compared, Garcia and colleagues [10-12] were able to identify a few conserved pairs of interactions (TCR:MHC) that represented germline-encoded recognition motifs. Several amino acid residues of the complementarity determining region 1 (CDR1) and CDR2 loops contacted the helices of the MHC and these interactions were important energetically. Accordingly, it was proposed that each $\mathrm{V}$ region might have evolved a few key 
Figure I. Germline-encoded residues in CDRI and/or CDR2 of TCR variable (V) regions evolved to interact with MHC

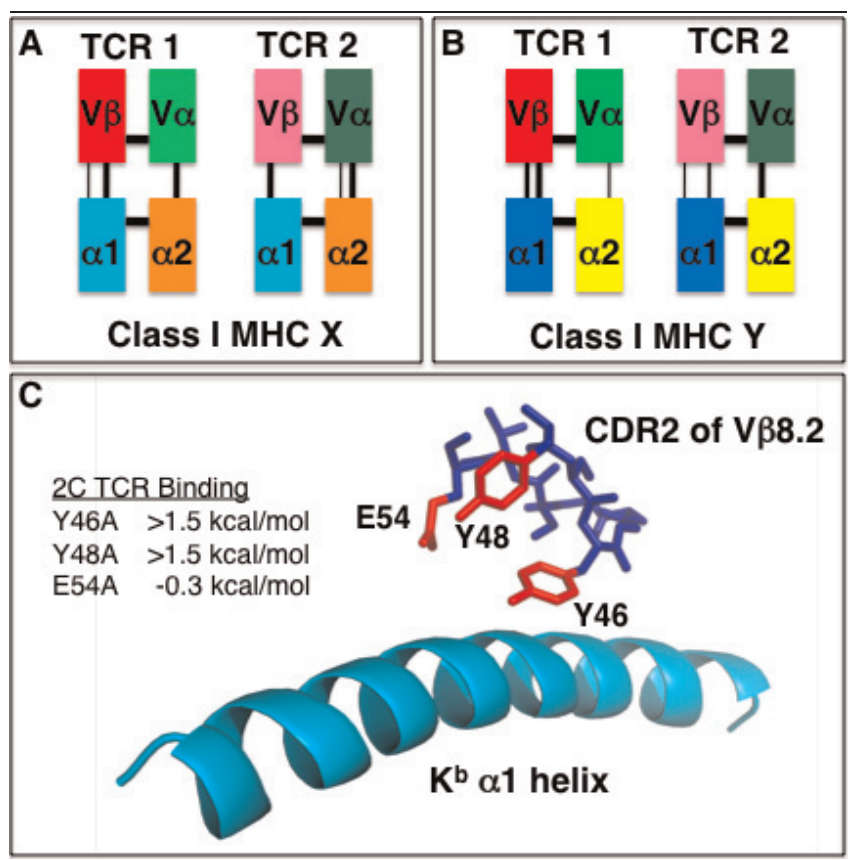

(a) A class I MHC allele $(X)$ is contacted by a few residues from the $V \alpha$ and $\mathrm{V} \beta$ of TCRI. A different TCR, TCR 2, might contain different residues from its $\mathrm{V} \alpha$ and $\mathrm{V} \beta$ that contact the same MHC allele. The lines extending between $\mathrm{V}$ regions and $\mathrm{MHC}$ helices represent atomic interactions of varying strengths (denoted by widths). (b) The same TCRs from (a) might have evolved a slightly modified set of residue interactions with a different MHC allele (Y). (c) In the structure of the 2C TCR:SIY/K $K^{b}$, the CDR2 $\beta$ loop contains three residues, $Y 46, Y 48$, and E54, that have been implicated in the positive selection of class I and/or II molecules. In an alanine scan of the $2 \mathrm{C}$ TCR, residues $Y 46$ and $Y 48$ were shown to contribute significant binding energy, whereas E54 did not. As described in the 'A case for both mechanisms' section, only a few atomic interactions such as these could contribute the majority of the binding energy in positive selection. CDR, complementarity determining region; MHC, major histocompatibility complex; TCR, T-cell receptor.

residues that contribute binding energy with the helix of an MHC molecule (Figure 1a,b). In this model, it has been suggested that the same $\mathrm{V}$ region might have evolved different contacts with a different allele, as in the case of the 2C TCR recognizing $\mathrm{K}^{\mathrm{b}}$ compared with $\mathrm{L}^{\mathrm{d}}$ [13]. To date, these TCR regions have focused mostly on the V $\beta$, although there is some evidence that $\mathrm{V} \alpha$ regions may also be involved $[5,14]$. Thus, the conserved diagonal orientation of TCRs on MHC could be a consequence of these evolution-driven V-region interactions with the corresponding helices of the class I or class II MHC ligands.

Kappler, Marrack, Gapin, and their colleagues soon verified this result at the structural level $[15,16]$ and provided a comparative analysis of conserved amino acid residues among the repertoire of V-region genes [14]. In a key follow-up to the structural studies, they recently reported that the mutation of several of these conserved residues in V $\beta 8.2$ (see 'A case for both mechanisms' section below) also had a significant quantitative impact on the positive selection of thymocytes [17], providing evidence of the physiological importance of these residues in interactions with MHC.

Finally, in a series of studies by Rossjohn, McCluskey, and colleagues [18], it is clear that the biased usage of TCR gene segments against a specific pepMHC is a product of many factors, including the antigen peptide itself and the MHC-restricting element. In a recent study comparing the structures of two Epstein-Barr virus (EBV)-specific TCRs, they showed that the process of negative selection (in their example, against an MHC allotype) had a significant impact on the ultimate repertoire of EBV-reactive TCRs that emerged [19]. A corollary of these findings is that evolution-driven TCR V-region binding to particular MHC alleles could be so strong as to lead to the deletion of $\mathrm{T}$ cells bearing these TCRs in the thymus. It is important to note that this same group has shown that at least some TCR:pepMHC interactions have energetic profiles that focus more on CDR3 interactions rather than those of CDR1 and CDR2 [20]. Thus, a strict evolution-based model of germline V-region interactions for all TCRs may be an overgeneralization. In these cases, the co-receptor mechanism described below may be more critical.

\section{CD4 and CD8 co-receptors ensure $\mathrm{MHC}$ restriction of TCRs}

An alternative mechanism that could drive the conserved docking orientation, and one that (in principle) is consistent with the absence of universally conserved atomic interactions, involves the requirement for coreceptors CD4 and CD8 [21,22]. Recently, Singer and colleagues [23] generated mice deficient in CD4, CD8, class I MHC, and class II MHC and showed that the mice contained a diverse repertoire of $\mathrm{T}$ cells that were not restricted by MHC. To account for this, they proposed that sequestration of the lymphocyte-specific tyrosine kinase (Lck) by CD 4 and CD8 can dictate selection for TCR:MHC binding by preventing signalling by non-MHC ligands.

In this model, only TCRs that bind to an MHC molecule will be capable of bringing the CD4 or CD8 molecules into proximity with the TCR/CD3 complex, thereby allowing the associated Lck to initiate the signalling process through CD3 (Figure 2a). Those TCRs that bind to non-MHC molecules would not be capable of recruiting CD4/Lck or CD8/Lck to the TCR/CD3 complex (Figure 2b). If one assumes that co-receptor and/or CD3 
Figure 2. The requirement for CD4 or CD8 binding to MHC ensures that the TCR does not interact with non-MHC ligands

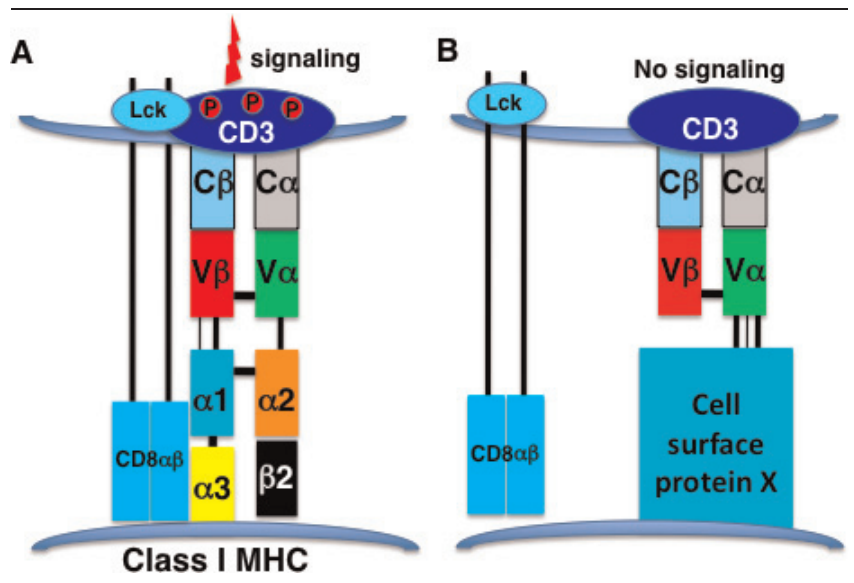

(a) When the TCR has some minimal affinity for a class I MHC, CD8 binding to the same $\mathrm{MHC}$ molecule drives the proximal signalling necessary for positive selection through the action of the associated kinase Lck that phosphorylates CD3 subunits. (b) When the TCR binds to a non-MHC ligand, the CD8/Lck complex is unable to associate with the TCR/CD3 complex and signalling does not occur. Lck, lymphocyte-specific tyrosine kinase; MHC, major histocompatibility complex.

must be positioned sterically to allow simultaneous binding of the TCR and co-receptor to the same MHC molecule, then one could imagine the need for a conserved diagonal imprint of TCR on the pepMHC.

\section{A case for both mechanisms: affinity threshold of positive selection, TCR diversity, and binding energetics}

Which of these two mechanisms is more important for MHC restriction by $\mathrm{T}$ cells? The discussion to follow is based on two primary considerations. First, the TCR: MHC interaction affinity required for positive selection has been evolutionarily set to be quite low [24]. Second, the extensive diversity of TCRs, like antibodies, is likely to allow low-affinity interactions with many different ligands (sometimes referred to as polyspecificity [25]).

As indicated above, the affinity threshold for positive selection has been estimated to be quite low (in the range of $\left.10^{4} / \mathrm{M}\right)[26,27]$. Thus, thymocytes have evolved an exquisite sensitive mechanism for guiding the selection process [28]. This low affinity threshold allows a set of minimal conserved interactions between TCR and MHC to be effective. In this regard, it is worth considering whether the proposed evolution-driven atomic interactions (for example, Y46 and Y48 of mouse V38.2) contribute sufficient binding energy to drive positive selection. Alanine scans of the 2C TCR, which contains V $\beta 8.2$ and has been studied in detail structurally $[13,29,30]$, have been performed for binding to both a syngeneic ligand $\mathrm{K}^{\mathrm{b}}$ and an allogeneic ligand $\mathrm{L}^{\mathrm{d}}$ $[31,32]$. The binding energies associated with the two key CDR2 $\beta$ residues Y46 and Y48 (Y48 and Y50 in $[31,32]$ ) were each shown to be $1.5 \mathrm{kcal} / \mathrm{mol}$ or greater (that is, no binding was observed for the alanine mutants) (Figure 1c). Another residue in CDR2 $\beta$ of V $\beta 8.2$ which has been shown to be important in class II binding, E54, was actually shown to have a negative effect on binding to QL9/ $\mathrm{L}^{\mathrm{d}}$ (residue E56 in $[31,33]$ ), and mutation of this residue to alanine had a diminished effect on positive selection of $\mathrm{CD}^{+}$cells in the recent work [17].

The net effect of the two residues Y46 and Y48 (assuming no cooperative effects) would be at least $3 \mathrm{kcal} / \mathrm{mol}$. Residue $\mathrm{N} 29 \beta$ (N31 $\beta$ in [31]) also had an impact of $1.5 \mathrm{kcal} / \mathrm{mol}$, and several Vo3.1 CDR1 and CDR2 residues had significant effects. Are the binding energies associated with only a few atomic interactions sufficient to make a substantial contribution, perhaps even the dominant contribution, to positive selection? Based purely on the TCR:MHC affinities reported to be responsible for positive selection, the answer is yes. Thus, at a $\mathrm{K}_{\mathrm{A}}$ value of $10^{4} / \mathrm{M}$, the binding free energy of positive selection interactions would be in the range of $5.4 \mathrm{kcal} / \mathrm{mol}$ (calculated from $\Delta \mathrm{G}=-\mathrm{RT} \ln \mathrm{K}_{\mathrm{A}}$ ). Even the interactions associated with only $\mathrm{Y} 46 \beta, \mathrm{Y} 48 \beta$, and $\mathrm{N} 29 \beta$ would contribute the majority of this binding energy. Clearly, the basal binding energies associated with conserved interactions would be influenced, either negatively or positively, by adjacent CDRs (including CDR3s) or by the peptide bound to the MHC product $[18,20,34,35]$.

What would be the probability that a TCR would have a basal binding affinity of $10^{4} / \mathrm{M}$ for an MHC molecule if there were not an evolutionarily-based selection of $\mathrm{V}$ region:MHC interactions? While there are no data to provide guidance here, it would seem that this would be a highly infrequent event and that reliance on random chance would be a considerable waste in terms of the number of thymocytes necessary to yield such interactions. Furthermore, the conserved diagonal docking angle indicates that orientation is not random, further reducing the probability of a chance encounter with adequate affinity between TCR and MHC (that is, in just the right orientation).

Notwithstanding the arguments in favor of evolved $\mathrm{V}$ region:MHC binding interactions, the low affinity threshold of positive selection also requires that a mechanism be in place to ensure that TCR interactions with non-MHC ligands do not lead to positive selection. The very same TCR diversity that allows a broad response against foreign antigens would enable such interactions. 
While we are unaware of any studies that have assessed the frequency of such reactivities of the TCR repertoire, it is useful to examine what we know about this with antibodies, since germline (non-mutated) antibodies are similar to TCRs in terms of diversity. It has been reported that a single germline antibody could react with up to $1 \%$ of a protein library derived from cDNA [36]. (Note: the affinities of these interactions were not reported, but it is reasonable to guess that they were at least $10^{4} / \mathrm{M}$ or binding would not have been detected.) Furthermore, it has been shown that diversity in a single $\mathrm{CDR} 3_{\mathrm{H}}(\mathrm{CDR}$ of the antibody heavy chain) region (that is, identical germline regions) was capable of generating reactivity with virtually any antigen tested [37].

Accordingly, it is reasonable to predict that TCRs would have a high frequency of low affinity for other cell surface molecules (consistent with the observations in [23]). The low affinity threshold necessary for positive selection makes it even more likely that such interactions would occur. Thus, it is imperative that a precise mechanism such as CD4/CD8 co-receptor sequestration of Lck be in place to avoid positive selection of TCRs with such reactivities, even if the V-region repertoire has been evolutionarily selected for interactions with MHC.

\section{Future directions}

To further support the concept of evolution-driven $\mathrm{V}$ region:MHC interactions, it will be important to examine many more structures of TCR:pepMHC complexes, focusing on TCRs with the same $\mathrm{V}$ region $(\mathrm{V} \alpha$ and/or $\mathrm{V} \beta$ ) in complexes with diverse ligands. These ligands should include different peptides bound to the same MHC, different MHC alleles, and both class I and class II MHCs. It would also be useful to examine TCRs isolated through in vitro selections of germline $\mathrm{V}$-region libraries [38] for binding to MHC products, in the absence of coreceptors. This could reveal the role of CD4 or CD8 in guiding the docking orientation (for example, if the diagonal were not observed, one would predict a significant role of CD4 and CD8). Finally, additional thymic development studies with TCRs containing selected point mutations [17] would assess how broadly these findings can be extended to other $\mathrm{V}$ regions.

\section{Abbreviations \\ CDR, complementarity determining region; EBV, Epstein-Barr virus; Lck, lymphocyte-specific tyrosine kinase; MHC, major histocompatibility complex; pepMHC, peptide complexed with an MHC product; TCR, T-cell receptor; $\mathrm{V}$, variable.}

\section{Competing interests}

The author declares that he has no competing interests.

\section{Acknowledgments}

Discussions with Adam Chervin, Jennifer Stone, Herman Eisen, and Chris Garcia are greatly appreciated. This work was supported by National Institutes of Health grants R01 GM55767 and P01 CA097296.

\section{References}

I. Zinkernagel RM, Doherty PC: Restriction of in vitro $\mathbf{T}$ cellmediated cytotoxicity in lymphocytic choriomeningitis within a syngeneic or semiallogeneic system. Nature 1974, 248:701-2.

2. Jameson SC, Hogquist KA, Bevan MJ: Positive selection of thymocytes. Annu Rev Immunol 1995, I3:93-126.

3. Jerne NK: The somatic generation of immune recognition. Eur J Immunol 197I, I:I-9.

4. Blackman M, Yague J, Kubo R, Gay D, Coleclough C, Palmer E, Kappler J, Marrack P: The $T$ cell repertoire may be biased in favor of MHC recognition. Cell 1986, 47:349-57.

5. Sim B-C, Zerva L, Greene MI, Gascoigne NRJ: Control of MHC Restriction by TCR V $\alpha$ CDRI and CDR2. Science 1996, 273:963-6.

6. Zerrahn J, Held W, Raulet DH: The MHC reactivity of the T cell repertoire prior to positive and negative selection. Cell 1997 , 88:627-36.

7. Housset D, Malissen B: What do TCR-pMHC crystal structures teach us about MHC restriction and alloreactivity? Trends Immunol 2003, 24:429-37.

8. Garcia KC, Adams EJ: How the $\mathbf{T}$ cell receptor sees antigen-a structural view. Cell 2005, I 22:333-6.

9. Rudolph MG, Stanfield RL, Wilson IA: How TCRs bind MHCs, peptides, and coreceptors. Annu Rev Immunol 2006, 24:4I 9-66.

FI000 Factor 8.0 Exceptional

Evaluated by Jia-huai Wang 03 Feb 2006, Jamie Rossjohn 04 May 2006

10. Maynard J, Petersson K, Wilson DH, Adams EJ, Blondelle SE, Boulanger MJ, Wilson DB, Garcia KC: Structure of an autoimmune $\mathrm{T}$ cell receptor complexed with class II peptideMHC: insights into MHC bias and antigen specificity. Immunity 2005, 22:81-92.

FI000 Factor 6.4 Must Read

Evaluated by Kai Wucherpfennig 08 Feb 2005, Andrea Sant 18 Apr 2005

II. Feng D, Bond CJ, Ely LK, Maynard J, Garcia KC: Structural evidence for a germline-encoded $T$ cell receptor-major histocompatibility complex interaction 'codon'. Nat Immunol 2007, 8:975-83.

12. Garcia KC, Adams JJ, Feng D, Ely LK: The molecular basis of TCR germline bias for MHC is surprisingly simple. Nat Immunol 2009, 10:143-7.

13. Colf LA, Bankovich AJ, Hanick NA, Bowerman NA, Jones LL, Kranz DM, Garcia KC: How a single T cell receptor recognizes both self and foreign MHC. Cell 2007, I 29:135-46.

I4. Marrack P, Scott-Browne JP, Dai S, Gapin L, Kappler JW: Evolutionarily conserved amino acids that control TCR-MHC interaction. Annu Rev Immunol 2008, 26: I7|-203.

15. Dai S, Huseby ES, Rubtsova K, Scott-Browne J, Crawford F, Macdonald WA, Marrack P, Kappler JW: Crossreactive T Cells spotlight the germline rules for alphabeta $T$ cell-receptor interactions with MHC molecules. Immunity 2008, 28:324-34.

16. Scott-Browne JP, Matsuda JL, Mallevaey T, White J, Borg NA, McCluskey J, Rossjohn J, Kappler J, Marrack P, Gapin L: Germlineencoded recognition of diverse glycolipids by natural killer T cells. Nat Immunol 2007, 8: I I05-I3. 
17. Scott-Browne JP, White J, Kappler JW, Gapin L, Marrack P: Germline-encoded amino acids in the alphabeta T-cell receptor control thymic selection. Nature 2009, 458:1043-6.

18. Gras S, Kjer-Nielsen L, Burrows SR, McCluskey J, Rossjohn J: T-cell receptor bias and immunity. Curr Opin Immunol 2008, 20: I I 9-25.

19. Gras S, Burrows SR, Kjer-Nielsen L, Clements CS, Liu YC, Sullivan LC, Bell MJ, Brooks AG, Purcell AW, McCluskey J, Rossjohn J: The shaping of $\mathbf{T}$ cell receptor recognition by self-tolerance. Immunity 2009, 30:193-203.

20. Borg NA, Ely LK, Beddoe T, Macdonald WA, Reid HH, Clements CS, Purcell AW, Kjer-Nielsen L, Miles JJ, Burrows SR, McCluskey J, Rossjohn J: The CDR3 regions of an immunodominant $T$ cell receptor dictate the 'energetic landscape' of peptide-MHC recognition. Nat Immunol 2005, 6: I7I-80.

21. Killeen N, Moriarty A, Teh HS, Littman DR: Requirement for CD8-major histocompatibility complex class I interaction in positive and negative selection of developing $\mathbf{T}$ cells. J Exp Med 1992, I 76:89-97.

22. Killeen N, Littman DR: The regulation and function of the CD4 coreceptor during $\mathbf{T}$ lymphocyte development. Curr ToP Microbiol Immunol 1996, 205:89-106.

23. Van Laethem F, Sarafova SD, Park JH, Tai X, Pobezinsky L, Guinter TI, Adoro S, Adams A, Sharrow SO, Feigenbaum L, Singer A: Deletion of CD4 and CD8 coreceptors permits generation of alphabetaT cells that recognize antigens independently of the MHC. Immunity 2007, 27:735-50.

FI000 Factor 6.4 Must Read

Evaluated by David Kranz 06 Dec 2007, Edward Collins 03 Jan 2008

24. Alam SM, Travers PJ, Wung JL, Nasholds W, Redpath S, Jameson SC, Gascoigne NR: T cell receptor affinity and thymocyte positive selection. Nature 1996, 381:616-20.

25. Wucherpfennig KW, Allen PM, Celada F, Cohen IR, De Boer R, Garcia KC, Goldstein B, Greenspan R, Hafler D, Hodgkin P, Huseby ES, Krakauer DC, Nemazee D, Perelson AS, Pinilla C, Strong RK, Sercarz EE: Polyspecificity of $\mathbf{T}$ cell and $\mathbf{B}$ cell receptor recognition. Semin Immunol 2007, 19:216-24.

26. Davis MM, Boniface JJ, Reich Z, Lyons D, Hampl J, Arden B, Chien Y: Ligand recognition by alpha beta $\mathrm{T}$ cell receptors. Annu Rev Immunol 1998, 16:523-44.

27. Gascoigne NR, Zai T, Alam SM: T-cell receptor binding kinetics in T-cell development and activation. Expert Rev Mol Med 200I, 200I:I-I7.

28. Daniels MA, Teixeiro E, Gill J, Hausmann B, Roubaty D, Holmberg K, Werlen G, Hollander GA, Gascoigne NR, Palmer E: Thymic selection threshold defined by compartmentalization of Ras/MAPK signalling. Nature 2006, 444:724-9.

FI000 Factor 8.0 Exceptional

Evaluated by Robert Parton 19 Dec 2006, Brigitte Huber 19 Jan 2007

29. Garcia KC, Degano M, Pease LR, Huang M, Peterson P, Teyton L, Wilson IA: Structural basis of plasticity in $\mathbf{T}$ cell receptor recognition of a self peptide-MHC antigen. Science 1998, 279: $1166-72$.

30. Luz JG, Huang M, Garcia KC, Rudolph MG, Apostolopoulos V, Teyton L, Wilson IA: Structural comparison of allogeneic and syngeneic $\mathrm{T}$ cell receptor-peptide-major histocompatibility complex complexes: a buried alloreactive mutation subtly alters peptide presentation substantially increasing $\mathbf{V}$ (beta) interactions. J Exp Med 2002, 195: I I75-86.

31. Manning TC, Schlueter CJ, Brodnicki TC, Parke EA, Speir JA, Garcia KC, Teyton L, Wilson IA, Kranz DM: Alanine scanning mutagenesis of an alphabeta $T$ cell receptor: mapping the energy of antigen recognition. Immunity 1998, 8:4I3-25.

32. Lee PU, Churchill HR, Daniels M, Jameson SC, Kranz DM: Role of 2C $T$ cell receptor residues in the binding of self- and allo- major histocompatibility complexes. J Exp Med 2000, 191:1355-64.

33. Manning TC, Parke EA, Teyton L, Kranz DM: Effects of complementarity determining region mutations on the affinity of an alpha/beta $T$ cell receptor: measuring the energy associated with CD4/CD8 repertoire skewing. J Exp Med 1999, 189:46I-70.

34. Correia-Neves M, Waltzinger C, Mathis D, Benoist C: The shaping of the $T$ cell repertoire. Immunity 200I, I4:2I-32.

35. Huseby ES, Crawford F, White J, Marrack P, Kappler JW: Interfacedisrupting amino acids establish specificity between $\mathbf{T}$ cell receptors and complexes of major histocompatibility complex and peptide. Nat Immunol 2006, 7:1 I9I-9.

FI000 Factor 3.0 Recommended Evaluated by Jamie Rossjohn 14 Dec 2006

36. Manivel V, Sahoo NC, Salunke DM, Rao KV: Maturation of an antibody response is governed by modulations in flexibility of the antigen-combining site. Immunity 2000, 13:6I I-20.

37. $\mathrm{Xu} \mathrm{JL}$, Davis MM: Diversity in the CDR3 region of $\mathbf{V}(\mathbf{H})$ is sufficient for most antibody specificities. Immunity 2000, 1 3:37-45.

38. Holler PD, Holman PO, Shusta EV, O'Herrin S, Wittrup KD, Kranz DM: In vitro evolution of a $\mathbf{T}$ cell receptor with high affinity for peptide/MHC. Proc Natl Acad Sci U S A 2000, 97: 5387-92. 